\title{
BIBLIOGRAFÍA SOBRE TEMAS ÁRABES DEL SHARQ AL-ANDALUS (LEVANTE DE AL-ANDALUS)
}

\section{Apéndice $V$}

\author{
Por \\ MIKEL DE EPALZA \\ FRANCISCO FRANCO SÁNCHEZ
}

Siguiendo la línea marcada por la revista desde sus inicios, adjuntamos un nuevo listado para el Corpus Bibliográfico del Sharq Al-Andalus con 305 títulos. Incluimos especialmente las publicaciones y estudios que han visto la luz en el último año, añadiendo también otros estudios que en bibliografías anteriores no fueron reseñados.

Anunciamos para el próximo volumen 6 de la revista Sharq Al-Andalus. Estudios Árabes la publicación de unos extensos índices de personas, lugares y conceptos, índices complementarios de los existentes en la publicación inicial de EPALZA, Míquel de; PATERNA, M. ${ }^{a}$ Jesús; COUTO, Antonio: Moros y moriscos en el Levante Peninsular (Sharq Al-Andalus). Introducción Bibliográfica (Alicante, Instituto de Estudios Alicantinos, 1.083, 293 pp.). De este modo se verá facilitada sensiblemente la búsqueda a lo largo de estas cinco bibliografías ya publicadas y, en conjunto, se tendrá un más fácil acceso a las publicaciones reseñadas sobre un tema o asunto concreto.

\section{A}

3.781 ABADAL I VINYALS, Ramon d': Com Catalunya s'obrial món mil anys enrera, Barcelona, Rafael Dalmau Editor, 2. ${ }^{a}$ ed., 1967, 61 pp.

3.782 ACIEN ALMANSA, Manuel: «Sobre la emigración de mayurquíes a 
Al-Andalus. Los mayurquíes en la Almería Nașrí», $V$ Jornades d'Estudis Històrics Locals. Les Illes Orientals d'Al-Andalus i les seves relacions amb Sharq Al-Andalus, Mágrib i Europa Cristiana (ss. VIII-XIII), ed. a cura de Guillem ROSSELLÓ BORDOY, Palma de Mallorca, Institut d'Estudis Baleàrics, 1987, pp. 123-132.

3.783 AGUADÉ NIETO, Santiago: «Molino hidráulico y sociedad en Cuenca durante la Edad Media (1177-1300)», Anuario de Estudios Medievales, Barcelona-Madrid, 12, 1982, pp. 241-277.

3.784 ALBEROLA ROMA, Armando; GIMÉNEZ LÓPEZ, Enrique: "Relaciones entre Alicante y el Norte de África durante el reinado de Felipe V", España y el Norte de África, Granada, Universidad, I, pp. 407-413.

3.785 ALEMANY, Rafael: "La conquesta cristiana del Regne de València en la historiografía catalana medieval: L'Aiguadolç. Dossier: La Conquesta de València (1238), Marina Alta, n. ${ }^{\circ} 7$, tardor 1988, pp. 9-32.

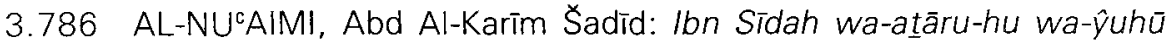
du-hu, (lbn Sída, su influencia y actividad), Bagdad, Ministerio de Cultura e Información, 1985.

3.787 ALOMAR,Gabriel: Urbanismo regional en la Edad Media: Las "Ordinacions" de Jaime // (1300) en el Reino de Mallorca, 1976, 120 pp.

3.788 ÁLVAREZ DE MORALES, Camilo: «Don Jacinto Bosch Vilá, Figueras, 1922-Granada, 1985", Estudios de Historia y de Arqueología Medievales, Cádiz, n. ${ }^{\circ}$ V-VI, 1985-1986, pp. 15-24.

3.789 ALVARO ZAMORA, M. ${ }^{a}$ Isabel: «La cerámica de Teruel», Cartillas Turolenses, Teruel, n. ${ }^{\circ} 8,1987$.

3.790 AMORES LLORET, Remedios: "Cerámica islámica estampillada de Murcia: Estudio tipológico, Boletín de la Asociación Española de Orientalistas, Madrid, n. ${ }^{\circ}$ XIII, 1987, pp. 101-118.

3.791 ARDIT LUCAS, Manuel: «Expulsió dels moriscos i creixement agrari al País Valencià», Afers. Homenatge al Dr. En Sebastià Garcia Martinez, Catarroja, vol. III. n. ${ }^{\circ}$ 5-6, 1987, pp. 273-316.

3.792 ARGENTE VIDAL, Javier: «Un libro de cuentas de las morerías del condado de Denia (1379)", Boletín de la Sociedad Castellonense de Cultura, Castellón, n. ${ }^{\circ}$ LXIII/III, jul.-sep. 1988, pp. 285-329.

3.793 ARIES, Ph.; DUBY, G. (dirs.): Historia de la Vida Privada. I. Del Imperio Romano al año mil, 1987, 640 pp.

3.794 ARROYO ILERA, Rafael: Las monedas valencianas, Valencia, Universidad Literaria, 1984, $182 \mathrm{pp}$.

3.795 ARROYOS SERRANO, Magín: "El "viratge filipi" en la política sobre els moriscos valencians, 1554-1564», Afers. Homenatge al Dr. En Sebastià Garcia Martinez, Catarroja, vol. III, n. ${ }^{\circ}$ 5-6, 1987, pp. 193-210.

3.796 AVILA, María Luisa: "El método historiográfico de Ibn Al-Abbār», Estudios onomástico-biográficos de Al-Andalus, Madrid, 1988, pp. 555-583. 
3.797 AYALA, Martín de: Doctrina Cristiana en lengua arábiga y castellana para instrucción de los moriscos, por el llmo. Sr. D. Martín de Ayala, Arzobispo de Valencia, ed. facsímil del original de 1911 en Valencia, Servicio de Reproducción de Librerías París-Valencia, 1980, $\mathrm{XIII}+31 \mathrm{pp}$.

\section{B}

3798 BACKMAN, Clifford R.: "Mudejars in the Criminal Laws of the Furs de València under Jaume I", Sharq Al-Andalus. Estudios Árabes, Alicante, $n^{\circ}$ 4, 1987, pp. 93-99.

3.799 BADÍA Y MARGARIT, Antoni M.: «Topònims àrabs i topònims mossàrabs a la Catalunya Nova", Homenaje a Álvaro Galmés de Fuentes, Madrid, ed. Gredos, 1987, pp. 593-600.

3.800 BALAÑA I ABADIA, Pere; GARCÍA I FORTUNY, Josep: "Els noms àrabs de la Xufla (Cyperus Esculentis L.)", Sharq Al-Andalus. Estudios Árabes, Alicante, n. ${ }^{\circ} 4,1987$, pp. 11-20. Cultivo de la chufa y preparación de la horchata en época islámica en el Sharq Al-Andalus.

3.801 BALAÑA | BADIA, Pere: «Fonaments per al coneixement de la Tortosa islàmica», $D(T)$, Tortosa, n. ${ }^{\circ} 2$, pp. 16-18.

3.802 BALAÑA I BADIA, Pere: "Jaume Caresmar: un cas inèdit d'arabofília al segle XVIIl", Miscel-lània d'Homenatge a Enric Moreu-Rey, Montserrat, Publicacions de l'Abadía de Montserrat, vol. I, 1988, pp. 135-151.

3.803 BAÑÓ I ARMINYANA, Ricard: Rutes históriques i monumentals d'Alcoi, Alcoi, Ajuntament, 1988, 148 pp. Mención de antecedentes islámicos.

3.804 BARCELÓ TORRES, Carmen: "Algunas notas sobre la ciudad islámi-. ca de Valencia», Estudios Medievales, Zaragoza, n. ${ }^{\circ} 11,1977$.

3.805 BARCELÓ, Carmen; LABARTA, Ana: «Fondos documentales árabes de la minoría musulmana en tierras valencianas", Sharq Al-Andalus. Estudios Árabes, Alicante, n. 4, 1987, pp. 101-107.

3.806 BARCELÓ TORRES, Carmen: "La làpida àrab del Museu de Xàbia», Xàbiga, Xàbia, n. ${ }^{\circ}$ 2, pp. 31-34.

3.807 BARCELÓ, M.; CARBONERO, M.: Les aigües cercades (Els qanāt(s) de l'llla de Mallorcal, Palma de Mallorca, 1986, 145 pp.

3.808 BARLES BAGUENA, Elena; BORRÁS GUALIS, Gonzalo M.; ÁLVARO

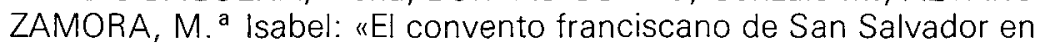
Pina de Ebro (Zaragoza)», Artigrama, Zaragoza, n. ${ }^{\circ} 3,1986$, pp. 49-103. Con una fábrica mudéjar originaria del segundo cuerto del S. XIV.

3.809 BATLLE, Carmen: «Las relaciones comerciales de Barcelona con la España musulmana a fines del siglo XII e inicio del XIII», Historia Medieval. Anales de la Universidad de Alicante, Alicante, n. ${ }^{\circ} 6,1987$, 
pp. 107-134.

3.810 BAZZANA, André; BERTRAND, Mayrelle; CRESSIER, Patrice; GUICHARD, Pierre; MONTMESSIN, Yves: "L'hydraulique agraire dans I'Espange médievale», L'eau et les hommes en Méditerranée, ed. André de RÉPARAZ, Marsella, ed. C.N.R.S., 1987, pp. 43-66.

3.811 BAZZANA, André: "Una noria árabe en la Huerta de Oliva (Valencia)", Arqueología Medieval Española. II Congreso. Madrid, 19-24 enero 1987. Tomo II: Comunicaciones, Madrid, ed. por la Conserjería de Cultura de la Comunidad de Madrid / Asociación Española de Arqueología Medieval, 1987, pp. 421-433.

3.812 BENITO IBORRA, Miguel: «Estudio preliminar de los hábitos alimenticios de origen animal de los moradores del poblado árabe de las Dunas de Guardamar (Alicante)», Arqueología Medieval Española. II Congreso. Madrid, 19-24 enero 1987. Tomo II: Comunicaciones, Madrid, ed. por la Conserjería de Cultura de la Comunidad de Madrid / Asociación Española de Arqueología Medieval, 1987, pp. 433-442.

3.813 BERNABÉ PONS, Luis Fernando: El cántico islámico del morisco hispanotunecino Taybili, Zaragoza, ed. Institución "Fernando el Católicon del C.S.I.C., 1988, 275 pp.

3.814 BENAVENT, Rafael: "Qatretonda: una nova vila del segle XV|», Estudis i Documents, Ontinyent, n. ${ }^{\circ} 3,1987$, pp. 22-25.

3.815 BERNABEU LÓPEZ, Rafael: "Andanzas de los moriscos por tierras requenenses", XVI Asamblea de Cronistas Oficiales del Reino de Valencia (Valencia, 9, 10, 11 y 12 octubre 1986), coord. por Santiago BRU I VIDAL, Valencia, ed. por la Consellería de Cultura / Diputación Provincial / Ayuntamiento de Valencia, 1988, vol. I, pp. 77-82.

3.816 BERNABEU RICO, J. L.: «La fiesta de los moros y cristianos en tierras valencianas», Anales de la Universidad de Alicante. Escuela de Magisterio, Alicante, n. ${ }^{\circ}$ 1. 1984, pp. 157-173.

3.817 BERTI; ROSELLÓ BORDOY, G.; TONGIORGI: «Alcuni bacini ceramici di Pisa e la corrispondente produzione di Maiorica nel secolo Xlı, Archeologia Medievale, n. ${ }^{\circ} 13,1986$, pp. 97-114.

3.818 BEUT । BELENGUER, Emili: "Conquesta de Castells valencians, 1084-1238", XVI Asamblea de Cronistas Oficiales del Reino de Valencia (Valencia, 9, 10, 11 y 12 octubre 1986), coord. por Santiago BRU I VIDAL, Valencia, ed. por la Consellería de Cultura / Diputación Provincial / Ayuntamiento de Valencia, 1988, vol. I, pp. 93-102. Progresión de la conquista del Sharq Al-Andalus hasta llegar a la ciudad de Valencia.

3.819 BLASCO, J.; CAMPS, C.; MONRAVAL, J. M.: "Reconstrucción de viviendas islámicas tras ser destruidas por una riada (s. XI)», Arqueología Medieval Española. II Congreso. Madrid, 19-24 enero 1987. Tomo ll: Comunicaciones, Madrid, ed. por la Conserjería de Cultura de la Comunidad de Madrid / Asociación Española de Arqueología Medieval, 1987, pp. 467-476. 
3.820 BLASCO GARCÍA, M. ${ }^{a}$ Carmen; NAVARRO I BELMONTE, Carmel: "Novelda durant l'etapa andalusí (segles VIII a XIII)", Betanis, Novelda, 1986, 5 pp.

3.821 BRAMON PLANAS, Dolors: «Aglutinación y deglutinación del artículo en los arabismos del castellano y del catalán», Vox Romanica, Bern, n. ${ }^{\circ} 46,1987$, pp. 138-179.

3.822 BRAMON PLANAS, Dolors: "Divertimento a l'entorn de Xàtiva i de la poesia valenciana escrita en àrab, Xàtiva, Xàtiva, 1982, pp. 64-73.

3.823 BRAMON, Dolors: «Zaragoza y Huesca, las dos ciudades aragonesas descritas en el tratado geográfico de Al-Zhurî (estudio de 8 de los 10 manuscritos)» Tvriaso. Monográfico «El Islam en Aragón», Tarazona, Centro de Estudios Turiasonenses de la Institución «Fernando el Católicon del C.S.I.C., n. ${ }^{\circ}$ 7, 1987, pp. 65-72.

3.824 BOIX, Manuel; PALACIOS, Josep: El Riu. Cinc dibuixos sobre una versió indirecta en llenguatge succesiu d'Ibn Hafadja, Ibn Amira i Ibn AlZaqqaq, poetes àrabs d'Alzira, amb el contrapunt dramàtic d'unes variacions, s. I., ed. Bromera, 1988, 20 pp.

3.825 BOLÓS, Jordi: "Fortificacions frontereres situades entre els rius Anoia i Gaià. L'estructuració d'un territori al segle X ", Arqueología Medieval Española. II Congreso. Madrid, 19-24 enero 1987. Tomo II: Comunicaciones, Madrid, ed. por la Conserjería de Cultura de la Comunidad de Madrid / Asociación Española de Arqueología Medieval, 1987, pp. 113-122.

3.826 BONMATÍ ANTÓN, José Fermín: «Fuentes para el estudio de la emigración de alicantinos a Argelia durante la época colonial», Sharq AlAndalus. Estudios Árabes, Alicante, n. ${ }^{\circ} 4$, 1987, pp. 21-29.

3.827 BORRÁS GUALIS, Gonzalo M.: «El arte mudéjar en Teruel y su provincia», Cartillas Turolenses, Teruel, n. " "extra" 3, 1987.

3.828 BRU I VIDAL, Santiago: "Toponímia urbana de l'antic Morvedre», Miscel/lània d'homenatge a Enric Moreu-Rey, Montserrat, Publicacions de l'Abadia de Montserrat, vol. 1, 1988, pp. 295-307.

3.830 BRUGUERA, Jordi: «Toponímia de la Crònica de Jaume i», Miscel lània d'homenatge a Enric Moreu-Rey, Montserrat, Publicacions de l'Abadia de Montserrat, vol. 1, 1988, pp. 309-333.

3.831 BUESA CONDE, Domingo J.: Teruel en la Edad Media, Teruel, 1980, $144 \mathrm{pp}$.

3.832 BURNS, Robert Ignatius: Alfonso the Learned: Emperor of Culture, Nueva York, Fordham Univ. Press., 1985, pp. 119.

3.833 BURNS, Robert Ignatius: "La conquesta de València: la dimensió Mariana", Món i Misteri de la Festa d'Elx, València, Consellería de Cultura de la Generalitat Valenciana, 1986.

3.834 BURNS, Robert Ignatius: "The Crusade aganist Al-Azraq: A ThirteenthCentury Mudejar Revolt in International perspective», American Historical Review, XC, 1988, pp. 80-106. 
3.835 BURNS, Robert Ignatius: "The friars of the Sack in Puigcerdà: A lost Chapter of 13th. -Century Religious History", Homenage al Dr. Emilio Sáez, Madrid, C.S.I.C., 1988.

3.836 BURNS, Robert Ignatius: "La guerra de Al-Azraq de 1249, Sharq AlAndalus. Estudios Árabes, Alicante, n. ${ }^{\circ} 4,1987$, pp. 253-256.

3.837 BURNS, Robert Ignatius: Islam bajo los Cruzados, Madrid, ed. El Albir, 1988.

3.838 BURNS, Robert Ignatius: «A lost Crusade: Unpublished Bulls of Innocent IV on Al-Azraq's revolt in 13th.-Century Spain», Catholical Historical Review, n. ${ }^{\circ}$ LXXIV, 1988.

3.839 BURNS, Robert Ignatius: "The Missionary Syndrome: Crusader and Pacific Nortwest Religious Expansionism», Comparative Studies in Society and History, XXX, 1988, pp. 271-285.

3.840 BURNS, Robert Ignatius: "Moorish Kingdoms of Spain», Dictionary of Middle Ages, ed. J. STRAYER, Nueva York, ed. Scribner's Sons, 1988.

3.841 BURNS, Robert Ignatius: "The Mudejars of Medieval Valencia: A Unique Community of Islam», Islam: Continuity and Change, ed. Thomas MICHEL, Roma, Centre d'Etudes pour le Monde Arabe Moderne, 1987, pp. 23-33. Reimpreso en Salaam, Nueva Delhi, Islamic Studies Association, n. ${ }^{\circ}$ Vill, 1987, pp. 189-198.

3.842 BURNS, Robert lgnatius: "Les mudéjares du royaume de Valence: une majorité traité en minorité», Minorités et Marginaux en France Mérdionale et dans la Péninsule lbérique (VII e-XIII ${ }^{e}$ siècles), ed. P. TOCOO CHALA \& M. LAMBERT-GORJES, París, C.N.R.S., 1986, pp. 95-118.

3.843 BURNS, Robert Ignatius: "The Mudejars of Sicily and Valencia", Proceedings, American Historical Association, 1985; también en Ann Arbor, University Microfilms, 1986.

3.844 BURNS, Robert Ignatius: «Príncipe almohade y converso mudéjar: nueva documentación sobre Abû Zayd", Sharq Al-Andalus. Estudios Árabes, Alicante, n. ${ }^{\circ} 4,1987$, pp. 109-122

\section{C}

3.845 CABANES PECOURT, $M{ }^{\text {a }}$ Desamparados: "Tarazona en la repoblación de 1389», Aragón en la Edad Media, Zaragoza, n. VII, pp. 39-46.

3.846 CABAÑERO SUBIZA, Bernabé; ESCRIBANO SÁNCHEZ, J. Carlos: "Problemática y fuentes de la cronología de la arquitectura aragonesa", Actas del III Simposio Internacional de mudejarismo (Teruel, 20-22 de septiembre de 1984), Teruel, Instituto de Estudios Turulenses, 1986, pp. 397-414. Especialmente arte mudéjar.

3.847 CABELLO GARCÍA, M. ${ }^{a}$ Sol: "Amirat Al-Andalus de Ahmad Šauqī", 
Sharq Al-Andalus. Estudios Arabes, Alicante, n. ${ }^{\circ} 4,1987$, pp. 31-34.

3.848 CALERO SECALL, M. ${ }^{a}$ Isabel: "Los Banū Sīd Būna», Sharq Al-Andalus. Estudios Árabes, Alicante, n. ${ }^{\circ} 4,1987$, pp. 35-54. Familia de místicos musulmanes originarios de la Vall de Guadalest.

3.849 CAMP JORDÁ, Fernando del: "Catálogo de los sistemas fortificados medievales en la comarca del Alto Ampurdán (Gerona): Castillos y villas amuralladas. Metodología para su estudio y conservación», Arqueología Medieval Española. II Congreso. Madrid, 19-24 enero 1987. Tomo 11: Comunicaciones, Madrid, ed. por la Conserjería de Cultura de la Comunidad de Madrid / Asociación Española de Arqueología Medieval, 1987, pp. 123-136.

3.850 CASANOVA, Emili: «Aproximació a una toponímia d'aigues en catalá al País Valencià», Agua y poblamiento musulmán. Aigüa i poblament musulmà (Simposioum de Benissa, abril 1987). Benissa, ed. Ajuntament, 1988, pp. 115-141.

3.851 CASANOVA, Emili: "Sobre Benissoda i els seus llinatges, 1609-1987", Estudis i Documents, Ontinyent, n. ${ }^{\circ}$ III, 1987, pp. 49-51.

3.852 CASIMIRO CAMPOS, José Carlos: "Un proceso repoblador en el señorío de Valldigna (1609-1648): Alcudiola y Masalalín, XVI Asamblea de Cronistas Oficiales del Reino de Valencia (Valencia, 9, 10, $11 \mathrm{y}$ 12 octubre 1986), coord. por Santiago BRU I VIDAL, Valencia, ed. por la Consellería de Cultura / Diputación Provincial / Ayuntamiento de Valencia, 1988, vol. I, pp. 141-152.

3.853 CATALÀ I FERRER, Enrique: "Las cerámicas musulmanas de la plaza de Sant Miquel, Cocentaina", Revista de Fiestas Moros i Cristians, Cocentaina, 1988, $7 \mathrm{pp}$.

3.854 CATALÀ I ROCA, Pere: De cara a la Mediterrània. Les torres del litoral català, Barcelona, Rafael Dalmau Editor, 1987, 99 pp.

3.855 CATALÀ I ROCA, Pere: Llegendes de castells catalans, Barcelona, Rafael Dalmau Editor, 1983, 125 pp.

3.856 CERVERA FRÍAS, M. ${ }^{a}$ José: "Los talismanes árabes de Tórtoles», Tvriaso. Monográfico "El Islam en Aragón», Tarazona, Centro de Estudios Turiasonenses de la Institución "Fernando el Católico» del . C.S.I.C., n. ${ }^{\circ}$ 7, 1987, pp. 225-274.

3.857 COMBA Y COMBA, Amelia: "El nombre de "Algar" en la Geografía española", Arqueología Medieval Española. II Congreso. Madrid, 19-24 enero 1987. Tomo II: Comunicaciones, Madrid, ed. por la Conserjería de Cultura de la Comunidad de Madrid / Asociación Española de Arqueología Medieval, 1987, pp. 153-157. Algar de Palancia (València), Algar de Mesa (Guadalajara), El Algar (Murcia), El Algar (isla de Mallorca), el río Algar (Alicante.

3.858 COOPER, Edward: «La construcción del Castillo de Villena por Juan Pacheco (1419-1474), primer Marqués de Villena», Congreso de Historia del Señorio de Villena, Albacete, Instituto de Estudios Albacetenses / C.S.I.C. / C.E.C.E.L., 1987, pp. 131-134. 
Reacondicionamiento del castillo almohade de La Atalaya de Villena.

3.859 CORRAL LAFUENTE, José Luis: "Cambios estructurales en Aragón mediados del siglo XII" , Aragón en la Edad Media. Estudios de Economía y Sociedad, Zaragoza, Depto. de Historia Medieval de la Universidad, n. ${ }^{\circ} \mathrm{V}, 1983$, pp. 95-112.

3.860 CORRAL LAFUENTE, José Luis; ESCOLANO, Severino: "Los musulmanes en Aragón», Tvriaso. Monográfico «El Islam en Aragón», Tarazona, Centro de Estudios Turiasonenses de la Institución «Fernando el Católico» del C.S.I.C., n. ${ }^{\circ} 7,1987$, pp. 5-8.

3.861 CORRAL LAFUENTE, José Luis: "El sistema urbano en la Marca Superior de Al-Andalus», Tvriaso. Monográfico "El Islam en Aragón», Tarazona, Centro de Estudios Turiasonenses de la Institución «Fernando el Católico» del C.S.I.C., n. ${ }^{\circ} 7,1978$, pp. 23-64.

3.862 CORRALES, E. M.: «ll commercio della Catalogna con il mondo islamico mediterraneo nel Settecento", Islam. Storia e Civiltà, Roma, anno VII, n. ${ }^{\circ} 1$, enero-marzo 1988.

3.863 CORRIENTE, Federico: «Toponimia hispano-árabe en Aragón (Marca Superior)», Tvriaso. Monográfico "El Islam en Aragón», , Tarazona, Centro de Estudios Turiasonenses de la Institución «Fernando el Católico" del C.S.I.C., n. ${ }^{\circ}$ 7, 1987, pp. 73-79.

3.864 CORTABARRÍA, Ángel: "Connaissance de l'Islam chez Raymond Lulle et Raymond Martin O. P. Parallèle», Cahiers de Fanjeaux. Raymond Lulle et le Pays d'Oc, Fanjeaux-Toulousse, C.N.R.S., n. ${ }^{\circ} 22,1987$, pp. 33-56.

3.865 COSTA CATALÀ, Juan: "ldentitat de la llengua valenciana», $\|^{\prime \prime n}$. Seminari de la Llengua Valenciana, Gandía, 1987, pp. 85-121.

3.866 CURTO HOMEDES, A.; MARTÍNEZ LANDÍN, R.: "Testimonis materials de la Tortosa andalusina», $D(T)$, Tortosa, n. ${ }^{\circ} 2,1987$, pp. 20-23.

3.867 CRUZ HERNÁNDEZ, M.: "La población peninsular durante los períodos visigodo y omeya y su influencia en los problemas de la Alta Edad Media», La Ciudad de Dios, Real Monasterio de San Lorenzo de El Escorial, vol. CXClil, n. ${ }^{\circ}$ 2, mayo-agosto 1980, pp. 259-295.

\section{$\mathrm{CH}$}

3.868 CHEJNE, Anwar G.: «Plegaria bilingüe árabe-aljamiada de un morisco» Homenaje a Álvaro Galmés de Fuentes, Madrid, ed. Gredos. vol. III., 1987, pp. 621-647.

3.869 CHERIF CHERGUI, Abderrahman: "Riflessioni su lbn 'Arabî, místico universale", Islam. Storia e Civiltà, Roma, 21, VI/4, ottobre-dicembre 1987, pp. 229-239. Comentario ecuménico islamo-cristiano a unos versos de este místico murciano del siglo XIII.

3.870 CHIRIBAY CALVO, Rafael: Las techumbres mudéjares instaladas en 
la Casa Consistorial de Zaragoza, Memoria de Licenciatura leída en la Universidad de Zaragoza en septiembre de 1986. Reseña la misma en la revista Artigrama, Zaragoza, 3, 1986, pp. 403-405. Fechadas en 1510-1515.

3.871 CHUECA GOITIA, Fernando: Aragón y la cultura mudéjar, Zaragoza, Institución "Fernando el Católico" del C.S.I.C., 20 pp.

\section{D}

3.872 DAVIS, Christopher: "The mudejars in the Crown of Aragon in the early Documents of Jaime the Conqueror (1218-1227)", Sharq A/Andalus. Estudios Árabes, Alicante, n. ${ }^{\circ}$ 4, 1987, pp. 123-130.

3.873 DELADRIERE, Roger: Ibn Arabî. La Proffession de Foi, París, ed. Sinbad, 1985.

3.874 DICKIE, J.: «The islamic garden in Spain», apud ETTINGHAUSEN, R.; MACDOUGALL, E. T.: The islamic Garden, Dumbarton Oaks Thustees for Harvard University, Washington, 1976.

3.875 DOMÍNGUEZ BEDMAR, Manuel: «Madinat Al-Mariyya. Estudio preliminar de las cerámicas aparecidas en sus atarazanas", Arqueología Medieval Española. II Congreso. Madrid, 19-24 enero 1987. Tomo 1I: Comunicaciones, Madrid, ed. por la Conserjería de Cultura de la Comunidad de Madrid / Asociación Española de Arqueología Medieval, 1987, pp. 567-579.

3.876 DUARTE I MONTSERRAT, Carles: "Notes sobre trets dialectals en el llibre de les costums de Tortosa", Caplletra, València, 2, primavera 1987, n. ${ }^{\circ}$ 19-26. Lista de arabismos de fines del siglo XIII.

3.877 DUFEIL, M. M.: "Vision de l'Islam depuis l'Europe au début du XIV e, sièclen, Cahiers de Fanjeaux. Islam et Chrétiens du Midi (XII ${ }^{-}$XIV e s.), Fanjeaux-Toulousse, C.N.R.S., n. ${ }^{\circ} 18,1983$, pp. 235-258.

3.878 DURÀN, Eulàlia: Les Germaníes als Països Catalans, Barcelona, ed. Curial, 1984, 558 pp. Ataques contra los moriscos.

\section{$E$}

3.879 EPALZA, Míkel de: «El agua en el derecho musulmán», Agua y poblamiento musulmán. Aigüa i poblament musulmá (Simposium de Benissa, abril 1987), Benissa, ed. Ajuntament, 1988, pp. 13-19.

3.880 EPALZA, Míkel de: "Anselm Turmeda", Escriptors de les Illes Balears, Departament de Llengua Catalana de la Universitat de les Illes Balears, Palma de Mallorca, 1985, pp. 10-11.

3.881 EPALZA, Míkel de: Anselm Turmeda. Llibre dels bons amonestaments $i$ altres obres, Palma de Mallorca, ed. Moll, 1987, 111 pp.

3.882 EPALZA, Míkel de; FRANCO SÁNCHEZ, Francisco: «Bibliografía so- 
bre temas árabes del Sharq Al-Andalus (Levante de Al-Andalus). Apéndice IV», Sharq Al-Andalus. Estudios Árabes, Alicante, n. ${ }^{\circ} 4,1987$, pp. 291.349.

3.883 EPALZA, Míkel de: «La caída de Valencia del 9 de octubre: un testigo árabe», Información. Especial 9 d'Octubre, Alicante, 9-10-1988, pág. 15.

3.884 EPALZA, Míkel de: «La cartografía mediterránea que fomenta racismos", Canelobre, Alicante, Instituto "Juan Gil Albert" de la Diputación Provincial de Alicante, n. ${ }^{\circ}$ 12/13, 1988, pp. 40-44

3.885 EPALZA, Míkel de: «Correspondencia del arabista mallorquín Artigas con el valenciano Borrull sobre la historia árabe valenciana (1828-1829)", Sharq Al-Andalus. Estudios Árabes, Alicante, n. ${ }^{\circ} 4$, 1987, pp. 235-239.

3.886 EPALZA, Míkel de: "Costas alicantinas y costas magrebies: el espacio marítimo musulmán según los textos árabes (2)", Sharq A/Andalus. Estudios Árabes, Alicante, n. ${ }^{\circ} 4,1987$, pp. 45-48.

3.887 EPALZA, Míkel de: «La dualidad Campello-Fahs en el espacio agrícola de Al-Andalus (Alicante, Castalla, Pedreguer, Madrid)», Sharq AlAndalus. Estudios Árabes, Alicante, n. ${ }^{\circ} 4$, 1987, pp. 159-173.

3.888 EPALZA, Míkel de: "Estudios Auro-Árabes en la Universidad de Alicante», Campus, Alicante, 10, invierno-primavera 1987, pp. 34-36.

3.889 EPALZA, Míkel de: «Funciones de enseñanza de las dos mezquitas sobre las murallas de la Alhambra», Homenaje al profesor Darío Cabanelas Rodríguez, O. F. M., con motivo de su LXX Aniversario, Granada, Universidad, 1987, vol. II, pp. 183-186. Comparaciones con las mezquitas de Guardamar del Segura.

3.890 EPALZA, Míkel de: «Investigación en la Universidad. El Departamento de Filologías Árabe, Catalana y Francesan, Campus, Alicante, n. ${ }^{\circ}$ 10, invierno-primavera 1987, pp. 27-28.

3.891 EPALZA, Míkel de: "El Islam aragonés, un Islam de frontera», Tvriaso. Monográfico "El Islam en Aragón», Tarazona, Centro de Estudios Turiasonenses de la Institución "Fernando el Católico" del C.S.I.C., n. ${ }^{\circ} 7,1987$, pp. 9-21.

3.892 EPALZA, Míkel de: "Jesus fill de Maria (Issa Ibn Miriam), segons els musulmans», Revista de Festes, Benissa, 1988, 1 pág.

3.893 EPALZA, Míkel de: "A modo de introducción. Es escritor Ybrahim Taybili y los escritores musulmanes aragoneses», en Luis F. BERNABÉ PONS, El cántico islámico del morisco hispanotunecino Taybili, Zaragoza, Institución Fernando el Católico, 1988, pp. 5-26.

3.894 EPALZA, Míkel de: «Els mossàrabs valencians i els topònims derivats de "Kanîsa" àrab", Miscel lània d'homenatge a Enric Moreu-Rey, Montserrat, Publicacions de l'Abadia de Montserrat, vol. I, 1988, pp. 149-153.

3.895 EPALZA, Míkel de; VILAR, Juan Bautista: Planos y mapas hispánicos 
de Argelia. Siglos XVI-XVIII. Plans et cartes hispaniques de l'Algerie. XVI ème. $X$ XIII eme siècles, Madrid, Ministerio de Asuntos Exteriores, 1988, 403 pp. + fotos. + ils.

3.896 EPALZA, Míkel de: "Santa Pola en época àrab», Festes 88. Comparsa Els Pescadors, Santa Pola, 1988, 2 pp.

3.897 EPALZA, Míkel de: "Seis personajes árabes nacidos en Laqant (Alacant, Alicante)", Revista Oficial. Moros y Cristianos, Alicante, 1988, $2 \mathrm{pp}$.

3.898 EPALZA, Míkel de: «El significat etimològic de Petrer: camí empedrat», Societat d'Onomàstica. Butlletí Interior, Barcelona, XXXI, març 1988, pp. 10-11.

3.899 EPALZA, Míkel de: "Topònims àrabs a Alacant i a Malta: Benissa d'Alacant i Benghissa de Malta», Canelobre, Alicante, Instituto "Juan Gil Albert", n. ${ }^{\circ}$ 12/13, 1988, pp. 196-198.

3.900 EPALZA, Míkel de: «La tumba de un santo musulmán en Benifato», Alcoy, Alcoy, abril 1988, pp. 264-265.

3.901 EPALZA, Míkel de: "Uso y abuso de la palabra «moro", Revista de Fiestas, Petrer, 1988, pág. 27.

3.902 EPALZA, Míkel de: "La Vall d’Albaida musulmana», Estudis i Documents, Ontinyent, IV, 1988, pp. 17-24.

3.903 EPALZA, Míkel de: "La vie publique musuimane: entre le respect de la profession de foi et l'acceptation des valeurs extra-islamiques", Le défi du fondamentalisme islamique, Ginebra, ed. Labor et Fides, 1988, pp. 53-62.

3.904 ESCARTÍ I SORIANO, Vicent J.: "La plaga de llangosta a La Ribera: Algemesí, 1756", Boletín de la Sociedad Castellonense de Cultura, Castellón, n. ${ }^{\circ}$ LXIII/III, jul.-sep. 1988, pp. 427-442. Origen marroquí y antecedentes árabes.

3.905 ESCÓ, Carlos; GUIRALT, Josep; SÉNAC, Philippe: Arqueología Islámica en la Marca Superior de Al-Andalus, Huesca, Diputación de Huesca, 1988, 189 pp.

3.906 ESCÓ, Carlos; SÉNAC, Philippe: «La muralla islámica de Huesca», Arqueología Medieval Española. II Congreso. Madrid, 19-24 enero 1987. Tomo 11: Comunicaciones, Madrid, ed. por la Conserjería de Cultura de la Comunidad de Madrid / Asociación Española de Arqueología Medieval, 1987, pp. 579-601.

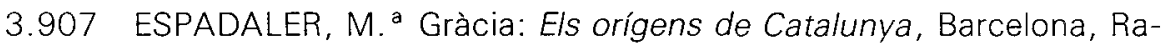
fael Dalmau Editor, 1984, 115 pp.

3.908 ESPI VALDÉS, Adrián: «Rasgos y motivos árabes en la pintura alcoyana", Boletín de la Asociación Española de Orientalistas, Madrid, VIII, 1972, pp. 226-233.

3.909 «Estudios islámicos en España. Un ejemplo: la Universidad de Alicanten, Antrohopos, suplemento n. ${ }^{\circ}$ 9: Miguel Cruz Hernández. Pensamiento Islámico. Investigación de su tradición y actualidad, Barcelona, 
Julio-agosto 1988, II-III.

3.910 EXPÓSITO, M.; PANO, J. L.; SEPÚLVEDA, M.: La Aljafería de Zaragoza. Guía histórico-artística y literaria, Zaragoza, ed. de Cortes de Aragón / Excmo. Ayuntamiento de Zaragoza, 1982, 152 pp.

\section{$\mathrm{F}$}

3.911 FEBRER ROMAGUERA, Manuel Vicente: "La organización judicial de la aljamas mudéjares valencianas y la "Suna e Xara" , XVI Asamblea de Cronistas Oficiales del Reino de Valencia (Valencia, 9, 10, 11 y 12 octubre 1986), coord. por Santiago BRU I VIDAL, Valencia, ed. por la Consellería de Cultura / Diputación Provincial / Ayuntamiento de Valencia, 1988, vol. I, pp. 193-217.

3.912 FERNÁNDEZ PUERTAS, Antonio: «Fondos numismáticos hispanomusulmanes del Museo de Cuenca", Cuadernos de la Alhambra, Granada, n. ${ }^{\circ} 18,1982$, pp. 115-142.

3.913 FERRÁN I GÓMEZ, Domènec: «Excavacions al recinte murat de la Tarrassa medieval», Arqueología Medieval Española. I/ Congreso. Madrid, 19-24 enero 1987. Tomo II: Comunicaciones, Madrid, ed. por la Conserjería de Cultura de la Comunidad de Madrid / Asociación Española de Arqueología Medieval, 1987, Pp. 161-168.

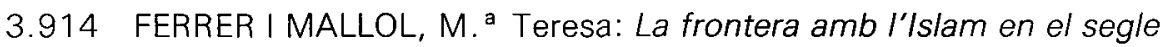
XIV. Cristians i Sarrains al País Valencià, Barcelona, Institució Milà i Fontanals del C.S.I.C., 1988, 533 pp.

3.915 FERRER I MALLOL, M. ${ }^{\text {a } T e r e s a: ~ E l s ~ S a r r a i n s ~ d e ~ l a ~ C o r o n a ~ C a t a l a n o-~}$ Aragonesa en el segle XIV. Segregació i discriminació, Barcelona, Institució Milà i Fontanals del C.S.I.C., 1987, 427 pp.

3.916 FERRER I MALLOL, M. ${ }^{a}$ Teresa: Les aljames sarraines de la Governació d'Oriola al segle XIV. Barcelona, Institució Milà i Fontanals del C.S.I.C., 1988.

3.917 FIERRO BELLO, M. ${ }^{a}$ Isabel: La heterodoxia en Al-Andalus durante el periodo omeya, Madrid, Instituto Hispano-Árabe de Cultura, 1987, 224 pp. Pocos ejemplos documentados en el Sharq Al-Andalus.

3.918 FONTENLA BALLESTA, Salvador: "Hallazgo de dirhems del emirato en el castillo de Aledo", Jarique, Madrid, n. ${ }^{\circ} 3$, abril 1988, pp. 4-7.

3.919 FONTENLA BALLESTA, Salvador: "Las monedas hispanomusulmanas del Museo de Murcia», Boletín de la Asociación Española de Orientalistas, Madrid, n. ${ }^{\circ}$ XIII, 1987, pp. 388-391.

3.920 FORNEAS, José M. ${ }^{a}$ : "El "Barnāmaŷ" de Muhammad lbn Ŷābīr AlWādi Āš̀̃. Materiales para su estudio y edición crítica», Al-Andalus, Madrid, XXXVIII, 1973, pp. 1-67. Biografías de Sharquíes.

3.921 FURIÓ, Antoni; GARCIA, Ferran: «Dificultats agràries en la formació i consolidació del feudalisme al País Valencià", Estudi General. La formació i consolidació del feudalisme català. Actes del Col-legi Universitari de Girona (8-11 de gener de 1985). Homenatge a Santiaqo 
Sobrequés i Vidal, edició a cura de Jaume PORTELLA I COMAS, G̈irona, n. ${ }^{\circ}$ 5-6, any 1985-86, pp. 291-310.

3.922 FRANCO SÁNCHEZ, Francisco: «El espacio del agua en la ciudad de Orihuela en época islámica», Agua y poblamiento musulmán. Aigüa i poblament musulmà (Simposium de Benissa, abril 1987), Benissa, ed. Ajuntament, 1988, pp. 33-53.

3.923 FRANCO SÁNCHEZ, Francisco: «La familia de los Síd Bono, unos santos árabes de Guadalest», Alcoy, Alcoy, abril 1988, pp 262-263.

3.924 FRANCO SÁNCHEZ, Francisco: "Noticia de Enguera en el siglo XIl», Enguera, Enguera, 1988, 4 pp.

\section{G}

3.925 GAFSI, Abdel-Hakim: «Algunas observaciones sobre el agua en las mezquitas de los pueblos andalusíes de Túnez», Agua y poblamiento musulmán. Aigüa i poblament musulmà (Simposium de Benissa, abril 1987), Benissa, ed. Ajuntament, 1988, pp. 55-58. En poblaciones tunecinas de moriscos originarios de Sharq Al-Andalus.

3.926 GALIAY SARAÑINA, José: El arte Mudéjar aragonés, Zaragoza, Institución Fernando el Católico, 272 pp.

3.927 GALLAT I FERNÁNDEZ, Josep; GARCÉS I ESTALLO, Ignasi: «Excavaciones en la calle Mayor de Lleida: nuevos datos para el conocimiento de la ciudad musulmana», Arqueología Medieval Española. II Congreso. Madrid, 19-24 enero 1987. Tomo II: Comunicaciones, Madrid, ed. por la Conserjería de Cultura de la Comunidad de Madrid I Asociación Española de Arqueología Medieval, 1987, pp. 638-648.

3.928 GALTIER MARTÍ, Fernando: "El verdadero castillo de Samitier», Tvriaso. Monográfico «El Islam en Aragón», Tarazona, Centro de Estudios Turiasonenses de la Institución "Fernando el Católico" del C.S.I.C., n. ${ }^{\circ}$ 7, 1987, pp. 159-194.

3.929 GARCIA BALLESTER, Luis: «La recepción del Colliget de Averroes en Montpellier (c. 1285) y su influencia en las polémicas sobre la naturaleza de las fiebres», Homenaje al Prof. Dario Cabanelas, Granada, Universidad, 1987, vol. II, pp. 317-332. Influencia en médicos catalanes como Arnau de Vilanova.

3.930 GARCÍA I FORTUNY, J.: «La matafaluga, el celiandre. Arrels islàmiques de la pastissería tradicional tortosina», $D(T)$, Tortosa, n. ${ }^{\circ} 2$, 1987, pp. 24-25.

3.931 GARCÍA GARIJO, Eneida: "La Alcoraya: Un espacio histórico agrícola y vial», Sharq Al-Aldalus. Estudios Árabes, Alicante, n. ${ }^{\circ} 4,1987$, pp. 153-158.

3.932 GARCIA GUATAS, Manuel; ESTEBAN, Juan F.: "Noticia sobre el hallazgo de un tejido musulmán", Artigrama, Zaragoza, n. ${ }^{\circ} 3,1986$, pp. 29-34. Tejido del s. XIl con la "basmalla", de la iglesia de Vells, 
en Huesca.

3.933 GARCÍA SERRANO, José Ángel: "Inscripción arábiga en una teja del Ayuntamiento de Novallas (Zaragoza)», Tvriaso. Monográfico «El /slam en Aragón", Tarazona, Centro de Estudios Turiasonenses de la Institución "Fernando el Católico" del C.S.I.C., n. ${ }^{\circ}$ 7, 1987, pp. 275-279.

3.934 GIL SAURA, Encarna; PERIS ALBENTOSA, Tomás: «El conflicto morisco en Valencia. Análisis de la dinámica del caso alcireño (Ribera Alta del Xúquer) a través de los cambios de propiedad”, España y el Norte de África, Granada, Universidad, 1987, vol. I, pp. 393-350.

3.935 GLICK, T. F.: Regadio y sociedad en la Valencia Medieval, traducción de A. ALMOR, ed. a cargo de R. FERRER NAVARRO, Valencia, $1988,414 \mathrm{pp}$.

3.936 GONZÁLEZ BALDOVÍ, Marià: "La influència de l'aigüa en la formación de la Xàtiva musulmana», Agua y poblamiento musulmán. Aigüa i poblament musulmà (Simposium de Benissa, abril 1987), Benissa, ed. Ajuntament, 1988, pp. 21-31.

3.937 GONZÁLEZ BLANCO, A.: Diccionario de la toponimia actual de La Rioja, Murcia, 1987, 618 pp.

3.938 GOZÁLVEZ GRAVIOTO, Carlos: «Notas sobre las funciones del albacar en las fortificaciones del Norte de África», Sharq Al-Aldalus. Estudios Árabes, Alicante, n. ${ }^{\circ}$ 4, 1987, pp. 199-202.

3.939 GUICHARD, Pierre: Estudios sobre historia medieval, Valencia, Institució Valenciana d'Estudis i Investigació, 1987, 264 pp.

3.940 GUICHARD, Pierre: "Participation des Méridionaux a la Reconquista dans le royaume de Valence", Cahiers de Fanjeux. Islam et Chrétiens de Midi (XI/ ${ }^{e} . X I V^{e}$. s.), Fanjeaux-Toulousse, C.N.R.S., n. ${ }^{\circ} 18$, 1983, pp. 115-131.

3.941 GUICHARD, Pierre: "La zone orientale de l'Espagne musulmane (Sharq Al-Aldalus), VIII ${ }^{\mathrm{e}}$. Xl11e. siècles", L'Arabisant, n. ${ }^{\circ}$ 26, 1987, pp. 11-16.

3.942 GUIRAL, Jacqueline: "L'aportació de les communautés jueva i musulmana al comerc martítim de València al segle XV", Afers. Homenatge al Dr. En Sebastià García Martínez, Catarroja, vol III, n. ${ }^{\circ}$ 5-6, 1987, pp. 33-46.

3.943 GUIRAL-HADZIIOSSIF, Jacquiline: Valence. Port méditerranéen au XVe. Siécle (1410-1525), París, Publications de la Sorbonne, 1986 , $555 \mathrm{pp}$.

3.944 GUTIÉRREZ LLORET, Sonia: "Avance para una tipología de las formas modeladas a mano del Ribat Califal de Guardamar del Segura (Alicante)". Arqueología Medieval Española. "/ Congreso. Madrid, 19-24 enero 1987. Tomo II: Comunicaciones, Madrid, ed. por la Conserjería de Cultura de la Comunidad de Madrid / Asociación Española de Arqueología Medieval, 1987, pp. 690-704. 
3.945 GUTIÉRREZ VELASCO, Antonio: «Pedro IV y los musulmanes. Maniobras diplomáticas del "Ceremonioso" (Años 1357-1358)", Revista de Historia "Jerónimo Zurita», Zaragoza, Instituto "Fernando el Católico» del C.S.I.C., 1986, n. ${ }^{\circ}$ 53-54, pp. 37-42.

\section{$\mathrm{H}$}

3.946 HERRERO ALONSO, Abelardo: "Valoración lingüística de la toponimia (aplicaciones a la toponimia valenciana en general y a La Safor

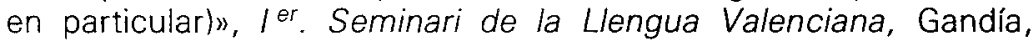
1986, pp. 111-125.

3.947 "Un islamólogo español: Míkel de Epalza», Antrohopos, suplemento n. ${ }^{\circ}$ 9; Miguel Cruz Hernández. Pensamiento Islámico. Investigación de su tradición y actualidad, Barcelona, julio-agosto 1988, Iil-IV.

3.948 İ̃̃IGUEZ ALMECH, Francisco: Asi fue la Aljafería, Zaragoza, Institución Fernando el Católico, 52 pp.

3.949 Î̃NIGUEZ ALMECH, Francisco: El castillo de la Aljafería, Zaragoza, Institución Fernando el Católico, 52 pp.

3.950 JANER, Florencio: Condición social de los moriscos de España: Causas de su expulsión y consecuencias que ésta produjo en el orden económico y político, Barcelona, ed. La Fulia, 1987, 578 pp. Edición facsímil de la original de Madrid de 1857.

3.951 JENÉ, Aurèlia; "La conquesta de Manûrqa el febrer de 1287», Estudi General. La formació i expansió del feudalisme català. Actes del Collegi Universitari de Girona (8-11 de gener de 1985). Homenatje a Santiago Sobrequés i Vidal, edició a cura de JAUME PORTELLA I COMAS, Girona, n. ${ }^{\circ}$ 5-6, any 1985-86, pp. 389-401.

3.952 JOVER I DOMÍNGUEZ, Francesc: "La tradició vinatera del Comtat», Alberri, Cocentaina (El Comtat), Ajuntament / Centre d'Estudis Contestans, n. ${ }^{\circ} 1,1988$, pp. 123-163. Datos sobre los musulmanes y moriscos.

3.953 LABARTA, Ana: «Marroquíes en la zona valenciana en la segunda mitad del siglo XVI», España y el Norte de África, Granada, Universidad, 1987, I.

3.954 LABARTA, Ana; BARCELÓ, Carmen: Números y cifras en los documentos arábigohispanos, Córdoba, Universidad, 1988,64 pp. + figs. Especialmente de Valencia y Mallorca. 
3.955 LAVAJO, Joaquim Chorao: Cristianismo e Islamismo na Península Ibérica: Raimundo Martí, un predecesor do diálogo religioso, Tesis Doctoral leída en la Universidad de Évora en 1988, 3 vols.

3.956 LÁZARO CERDÁ, Josefina: "Ador, unas tradiciones perdidas", XVI Asamblea de Cronistas Oficiales del Reino de Valencia (Valencia, 9 , 10,11 y 12 octubre 1986), coord. por Santiago BRU I VIDAL, Valencia, ed. por la Consellería de Cultura / Diputación Provincial / Ayuntamiento de Valencia, 1988, vol. I, pp. 231-242. Moros y Cristianos.

3.957 LEWIS, B. (editor y traductor): Islam from the Prophet Muhammad to the capture of Constantinople. Vol. I: Politic and War. Vol. 11: Religion and Society, New York / Oxford, 1987, 2 vols. (266 + 310 pp.).

3.958 LÓPEZ DEL ÁLAMO, Paloma: «La cerámica andalusí de vedrío melado en el siglo XI: estado de la cuestión". Arqueología Medieval Española. II Congreso. Madrid, 19-24 enero 1987. Tomo II: Comunicaciones, Madrid, ed. por la Conserjería de Cultura de la Comunidad de Madrid / Asociación Española de Arqueología Medieval, 1987, 731-743 pp.

3.959 LOMBA FUENTES, Joaquín: "Prefacio de "Los deberes de los corazones" de Ibn Paqûda", Tvriaso. Monográfico "El Islam en Aragón", Tarazona, Centro de Estudios Turiasonenses de la Institución "Fernando el Católicon del C.S.I.C., n. ${ }^{\circ} 7,1987$, pp. 195-224. Literato judío del s. XI, originario de la Zaragoza islámica.

\section{M}

3.960 MÁÑEZ INIESTA, Francisco: "Alfaquíes de Petrer», Revista de Fiestas, Petrer, 1988, pp. 34-35.

3.961 MÁÑEZ INIESTA, Francisco: «Batrir», Revista de Fiestas, Petrer, 1985, 1 pág. Notas tomadas en unas conferencias sobre el urbanismo musulmán de Petrer

3.962 MÁÑEZ INIESTA, Francisco: «Cronología de la marcha de Tarik Ben Ziyad desde Ceuta a Toledo y los Pirineos", Bodas de Plata. Comparsa Moros Beduinos, Petrer, 1988, 2 pp.

3.963 MARTÍN CORRALES, Eloy: «Aproximación a estudio del Corsarismo español en el litoral norteafricano en el siglo XVIIl», Aldaba, Melilla, U.N.E.D., año $V$, n. $^{\circ}$ 9, 1987, pp. 25-39.

3.964 MARTÍN CORRALES, Eloy: "La Bandera del Marroc i els "Camarades Moros": La participació marroquina a les files falangistes", L'Avenc, Barcelona, nov. 1987, n. ${ }^{\circ}$ 109, pp. 20-25

3.965 MARTÍN CORRALES, Eloy: «El comercio de Cataluña con Marruecos a finales del siglo XVIII (1767-1808)", Congreso Internacional sobre el Estrecho de Gibraltar. Ceuta, noviembre 1987, Granada, U.N.E.D., 1988, pp. 159-173.

3.966 MARTÍN CORRALES, Eloy: "El comercio de Barcelona con el Medite- 
rráneo Musulmán (1782-1808)», Pedralbes. Revista d'Història Moderna, Barcelona, n. ${ }^{\circ}$ 6, 1986, pp. 253-256.

3.967 MARTÍN CORRALES, Eloy: «El comerç de Catalunya amb els països musulmans al segle XVIIl», L'Avenç, Barcelona, octubre 1987, n. ${ }^{\circ}$ 108, pp. 26-32.

3.968 MARTIN CORRALES, Eloy: "Dos obstáculos en las relaciones comerciales entre Catalunya y los países musulmanes en el siglo XVIII: El Corso y la peste», Primer Congrés d'Història Moderna de Catalunya, Barcelona, 1984, vol. I, pp. 611-617.

3.969 MARTÍN CORRALES, Eloy: "Una oportunitat perduda per Barcelona per articular l'eix comercial índies-Llevant», llones. Jornades d'Estudis Catalano-Americanes (Barcelona, Maig, 1986), Barcelona, 1987, pp. 217-227. A fines del s. XVIII-comienzos del s. XIX.

3.970 MARTÍN PASCUAL, Llúcia: El deute de la Història de Jacob Xalabín amb la tradició oriental. Extensió i límits, Memoria de Licenciatura leída en la Universidad de Alicante en septiembre de 1988, 139 pp.

3.971 MARTÍN PASCUAL, Llúcia: «Reunió tècnica per la normalització de noms i textes d'origen àrab", Sharq Al-Andalus. Estudios Árabes, Alicante, n. ${ }^{\circ} 4,1987$, pp. 367-383.

3.972 MARTín PASCUAL, Llúcia: "Ús i abús del mot "moro"", Alcoy, Alcoy, abril 1988, pág. 261.

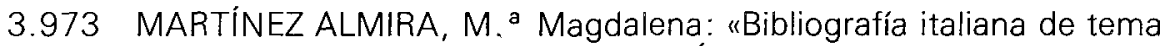
árabe», Sharq Al-Andalus. Estudios Árabes, Alicante, n. ${ }^{\circ} 4,1987$, pp. 361-363.

3.974 MARTINEZ, M.: La industria del vestido en Murcia (ss. XIII-XV), Murcia, 1988, $454 \mathrm{pp}$.

3.975 MARTÍNEZ MARTÍNEZ, M: «Molinos hidráulicos en Murcia (ss. XIIIXV)», Miscelánea Medieval Murciana, Murcia, 1987-88, pp. 219-250.

3.976 MARTÍNEZ PÉREZ, Antonio: Les cases de Moncada (Alzira, València), Alzira, Ajuntament, 1987, 145 pp. Elements àrabs d'un topònim i d'un $l l o c$ arqueològic.

3.977 MAS MARTÍNEZ, Vicente: "En torno a la figura de Muhammad AlShafra», Revista de Fiestas, Crevillente, 1987, 1 pág.

3.978 MCMILLIN, Linda A.: "Portrair of the Enemy: "Sarracens" in the Catalan Grand Chronicles», Sharq Al-Andalus. Estudios Árabes, Alicante, n. ${ }^{\circ} 4,1987$, pp. 49-57.

3.979 MEDINA, Francisco de Borja de: "La Compañía de Jesús y la minoría morisca (1545-1614), Archivium Historicum Societatis lesu, Roma, LVII, 1988, pp. 3-136. Particulares estudios sobre jesuitas y moriscos en regiones valencianas y murcianas.

3.980 MILLAS VALLICROSA, José M. ${ }^{a}$ : I. Estudios sobre historia de la ciencia española. II. Nuevos estudios sobre historia de la ciencia españo$1 a$, presentación de Juan VERNET, facsímil de las ediciones de 1949 y 1960,2 vols. 
3.981 MOLINA LÓPEZ, Emilio: "De nuevo sobre los beréberes. Reflexiones en torno a un proyecto de Atlas de Historia del Islam", Estudios de Historia y Arqueología Medieval, Cádiz, n. ${ }^{\circ}$ V-VI, 1985-86, pp. 25-31.

3.982 MOMBLANCH GARCIA, Francisco: «Aportaciones a la historia de Benilloba (II) «, XVI Asamblea de Cronistas Oficiales del Reino de Valencia (Valencia, 9, 10, 11 y 12 octubre 1986), coord. por Santiago BRU I VIDAL, Valencia, ed. por la Consellería de Cultura / Diputación Provincial / Ayuntamiento de Valencia, 1988, vol. I, pp. 339-354. Tras la expulsión de los moriscos, la repoblación.

3.983 MONTIEL, Juana: "Relación de textos en árabe del Archivo Municipal de Novelda», Betania, Novelda, 1986, 3 pp.

3.984 MOURELLE DE LEMA, Manuel: «El romance en el Reino de Valencia», IIón. Seminari de la Llengua Valenciana, Gandía, 1987, pp. 7-27.

3.985 MOURELLE DE LEMA, Manuel: «Proceso evolutivo de la lengua va-

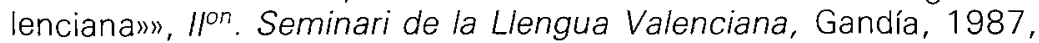
pp. $29-54$.

\section{N}

3.986 NAVARRO OLTRA, Vicente Carlos: «Un tesorillo de dirhems emirales en Pedreguer (Alicante)", Arqueología Medieval Española. I/ Congreso. Madrid, 19-24 enero 1987. Tomo III: Comunicaciones, Madrid, ed. por la Conserjería de Cultura de la Comunidad de Madrid / Asociación Española de Arqueología Medieval, 1987, pp. 54-61.

3.987 NAVARRO PALAZÓN, Julio; AMIGUES, François, GARCíA AVILÉS, Alejandro: "Arquitectura y artesanía en la Cora de Tudmîr", Historia de Cartagena, Muecia, ed. Mediterráneo, vol. 5, 1986, pp. 413-485.

3.988 NAVARRO POVEDA, Concepción: «Excavaciones en el castillo de Petrer», Revista de Fiestas, Petrer, 1988, pp. 28-31.

3.989 NAVARRO POVEDA, Concepción: «Los niveles islámicos del Castillo de la Mola, Novelda (Alicante)", Arqueología Medieval Española. II. Congreso. Madrid, 19-24 enero 1987. Tomo Il: Comunicaciones, Madrid, ed. por la Conserjería de Cultura de la Comunidad de Madrid I Asociación Española de Arqueología Medieval, 1987, pp. 63-71.

3.990 NAVARRO REIG, José: "Los mudéjares contestanos en el siglo XIIl", Historia Medieval. Anales de la Universidad de Alicante, Alicante, n. ${ }^{\circ}$ 6, 1987, pp. 175-206.

3.991 NEBOT CALPE, Natividad: «Léxico y locuciones autóctonas en las comarcas de habla castellano-aragonesa del antiguo Reino de Valencian, XVI Asamblea de Cronistas Oficiales del Reino de Valencia (Valencia, 9, 10, 11 y 12 octubre 1986), coord. por Santiago BRU I VIDAL, Valencia, ed. por la Consellería de Cultura / Diputación Provincial / Ayuntamiento de Valencia, 1988, vol. I, pp. 389-408. Vo- 
ces de origen árabe de las comarcas del Alto Mijares, Alto Palancia y la Serranía de Chelva.

\section{O}

3.992 ORTIZ DE GIL-MASCARELL, Luz: "Mudéjares y moriscos de Aljorf (Albaida)", Estudis i Documents, Ontiyent, n. ${ }^{\circ}$ III, 1987, pp. 71-75.

3.993 OUESLATI, Hedi: "Texto de un exiliado morisco en Túnez (siglo XVII)", Sharq Al-Andalus. Estudios Árabes, Alicante, n. ${ }^{\circ} 4,1987$, pp. 257-261.

\section{$\mathbf{P}$}

3.994 PADILLA, Paul: "El transporte de esclavos musulmanes a través de Valencia en los primeros años del reinado de Alfonso el Magnánimo, 1421-1440” Sharq Al-Andalus. Estudios Árabes, Alicante, n. ${ }^{\circ} 4$, 1987, pp. 59-72.

3.995 PALOMAR LLORENTE, M. ${ }^{a}$ Elisa; VILADÉS CASTILLO, José M. ${ }^{a}$ : "Cerámica de Manises en la excavación de la c. Mayor, 8 (Zaragoza)", Boletín de la Asociación Española de Orientalistas, Madrid, XXII, 1986, pp. 321-332.

3.996 PASCUAL MARTÍNEZ, Lope: «Los templarios en el Reino de Murcia», Homenaje al Prof. Muñoz Cortés, Murcia, Universidad, 1976-77, vol. II, pp. 871-886. En la frontera granadina, de 1266 a 1311.

3.997 PAVÓN MALDONADO, Basilio: «Arte islámico y mudéjar de Cuenca». Al-Qantara, Madrid, IV, 1983, pp. 357-376.

3.998 PAVÓN MALDONADO, Basilio: "La techumbre mudéjar de la Iglesia de la Sangre de Onda (Castellón) », Boletín de la Asociación Española de Orientalistas, Madrid, XIV, 1978, pp. 155-164.

3.999 PENYARROJA TORREJÓN, Leopoldo: "Origen y formación de la llengua valenciana (Des del substract ibèric a la Reconquista)", $l^{e r}$. Seminari de la Llengua Valenciana, Gandía, 1986, pp, 17-47).

4.000 PENYARROJA TORREJÓN, Leopoldo: "Mossarabisme i substrat (crítica retrospectiva)" " ${ }^{o ́ n}$. Seminari de la Llengua Valenciana, Gandía, 1987, pp. 55-84.

4.001 PEÑA GONZALVO, Javier: "La Seo del Salvador de Zaragoza (Análisis e hipótesis de su evolución constructiva desde su origen como mezquita aljama hasta el siglo XVII", Tvriaso. Monográfico "El Islam en Aragón", Tarazona, Centro de Estudios Turiasonenses de la Institución "Fernando el Católico" del C.S.I.C., n. ${ }^{\circ} 7,1978$, pp. 81-104.

4.002 PÉREZ BURGOS, José A.; RONDA FEMENIA, Ana: "Localizaciones acuifferas de Benissa y sus relaciones con el hábitat", Agua y poblamiento musulmán. Aigüa i poblament musulmà (Simposium de Re- 
nissa, abril 1987), Bénissa, ed. Ajuntament, 1988, pp. 59-65.

4.003 PINILLA PÉREZ DE TUDELA, Regina: "Crisis tras las Germanías en la morería de Alzira a través de los impuestos reales (1500-1536)», Al-Gezira. Revista d'Estudis Històrics. Ribera Alta, Alzira, n. ${ }^{\circ} 3$, oct. 1987, pp. 119-132.

4.004 PLA, Roberto: Muhyi I-Din Ibn Arabi. Tratado de la unidad, Málaga, Sirio D. L., 1987, 86 pp.

4.005 POCKLIGTON, Robert: «Antecedentes mozárabes y musulmanes del culto a San Ginés de la Jara», Historia de Cartagena, Murcia, ed. Mediterráneo, t. VI, 1986, pp 341-352.

4.006 POCKLINGTON, Robert: "El emplazamiento de lyi(h)", Sharq AlAndalis. Estudios Árabes, Alicante, n. ${ }^{\circ} 4$, 1987, pp. 175-198.

4.007 POCKLINGTON, Robert: Estudios toponímicos en torno a los orígenes de Murcia, Memoria de Licenciatura leída en la Universidad de Murcia, 1987, 208 pp.

4.008 POCKLINGTON, Robert: "La influència catalana en la toponímia de I'horta i el Camp de Múreia", Miscel.lània d'homenatge a Enric MoreuRey, Montserrat, Publicacions de l'Abadia de Montserrat, vol. II, 1988, pp. 43-62.

4.009 POCKLINGTON, Robert: «Toponimia islámica del Campo de Cartagena", Historia de Cartagena, Murcia, ed. Mediterráneo, t. VI, 1986. pp. 319-340.

4.010 POCKLINGTON, Robert: "Toponimia y sistemas de agua en el Sharq Al-Andalus", Agua y poblamiento musulmán. Aigüa i poblament musulmà (Simposium de Benissa, abril 1987), Benissa, ed. Ajuntament, 1988, pp. 103-114.

4.011 POVEDA NAVARRO, Antonio M. ${ }^{a}$ : "Aproximación a la demografía bajomedieval de la comarca del Medio Vinalopó (Alicante)", Historia Medieval. Anales de la Universidad de Alicante, Alicante, n. ${ }^{\circ} 6,1987$, pp. 31-48. Numerosa población mudéjar.

4.012 POVEDA NAVARRO, Antonio M. ${ }^{\text {a }}$ : El poblado ibero-romano de "El Monastil» (Elda. Alicante). Introducción Histórico-Arqueológica, Elda, Ayuntamiento / Univarsidad de Alicante, 1988, 154 pp. Se discute si el nombre es mozarabismo. Desaparición a la llegada del Islam, aunque aparezcan algunas piezas cerámicas musulmanas.

4.013 PETREL,MARÍN, Aurelio: «El nacimiento de Albacete», Cultural Albacete, Albacete, n. ${ }^{\circ}$ 3, abril 1986, pp. 3-21.

4.014 PUCHOL PÉREZ, J. V.: "Toponímia de Guadassuar: les partides rurals", Miscel-lània d'homenatge a Enric Moreu-Rey, Montserrat, Publicacions de I'Abadia" de Montserrat, vol. I, 1988, pp. 85-111.

\section{$\mathbf{R}$}

4.015 RIBERA I GÓMEZ, Agustí: «La Vila d'Ontinyent: una aproximació al 
recinte murat medieval", Arqueología Medieval Española. I/ Congreso. Madrid, 19-24 enero 1987. Tomo II: Comunicaciones, Madrid, ed. por la Conserjería de Cultura de la Comunidad de Madrid / Asociación Española de Arqueología Medieval, 1987, pp. 251-262.

4.016 RIERA FRAU, M. ${ }^{a}$ Magdalena: "Cerámicas de forma abierta en Can Bordils (Palma de Mallorca)", Arqueología Medieval Española. I/ Congreso. Madrid, 19-24 enero 1987. Tomo II: Comunicaciones, Madrid, ed. por la Conserjería de Cultura de la Comunidad de Madrid I Asociación Española de Arqueología Medieval, 1987, pp. 105-110.

4.017 RIERA PALMERO, Juan: «Nota sobre moriscos y cristianos viejos en el obispado de Cartagena-Orihuela a mediados del siglo XVI», Investigaciones Históricas, Valladolid, n. ${ }^{\circ} 4$, pp. 41-50.

4.018 ROCHE, Anne: «Note sur Abdelwahab Meddeb: "Tombeau d'lon Arabi», Revue d'Études Palestiniennes, n. ${ }^{\circ} 27,1988$, p. 173.

4.019 RODRÍGUEZ CARREÑO, Ángel M.: «Conquesta i feudalització: el cas de Pollenca, Mallorca (1298-1304)n, Estudi General. La formació i expansió del feudalisme català. Actes del Col.loqui organitzat pel Col.legi Universitari de Girona (8-11 de gener de 1985). Homenatge a Santiago Sobrequés i Vidal, edició a cura de Jaume PORTELLA I COMAS, Girona, n. ${ }^{\circ}$ 5-6, any 1985-86, pp. 371-387.

4.020 RODRÍGUEZ MARTÍNEZ, Leonor Carmen: "Dos inscripciones árabes modernas en montañas de Alicanten, Sharq Al-Andalus. Estudios Árabes, Alicante, n. ${ }^{\circ} 4,1987$, pp. 385-391.

4.021 ROMÁN MILLÁN, Inmaculada; SESER PÉREZ, Rosa: AGULLÓ GARCÍA, Pilar: "Formas constructivas en alquerías valencianas de finales del siglo XV: Aportación documental", Arqueología Medieval Española. II Congreso. Madrid, 19-24 enero 1987. Tomo II: Comunicaciones, Madrid, ed. por la Conserjería de Cultura de la Comunidad de Madrid/ Asociación Española de Arqueología Medieval, 1987, pp. 653-660.

4.022 ROSSELLÓ BORDOY, Guillem: "Dubtes sobre toponímia de les illes Orientals», $V$ Jornades d'Estudis Històrics Locals. Les IIIes Orientals d'Al-Andalus i les seves relacions amb Sharq Al-Andalus, Màgrib i Europa Cristiana (ss. VIII-XIII), ed. a cura de Guillem ROSSELLÓ BORDOY, Palma de Mallorca, Institut d'Estudis Baleàrics, 1987, pp. 181-182

4.023 ROSSELLÓ BORDOY, Guillem: "Las cerámicas andalusíes y algunos problemas de terminología". Homenaje a Álvaro Galmés de Fuentes, Madrid, ed. Gredos, 1987, pp. 685-690.

4.024 ROSSELLÓ BORDOY, Guillem: «Excavaciones arqueológicas en Palma de Maliorca. Sondeos en el casco antiguo", Mayurqa, Palma de Mallorca, n. ${ }^{\circ} 21,1985-87$, pp. 45-76.

4.025 ROSSELLÓ BORDOY, Guillem: «Sharq Al-Andalus i la investigació arqueológica: estat de la qüestión, Estudi General. La formació i expansió del feudalisme català. Actes del Col-loqui organitzat pel Col.legi 
Universitari de Girona (8-11 de gener de 1985). Homenatge a Santiago Sobrequés i Vidal, edició a cura de Jaume PORTELA I COMAS, Girona, n. ${ }^{\circ}$ 5-6, any 1985-86, pp. 253-263.

4.026 RUBIERA MATA, M. ${ }^{a}$ Jesús: La arquitectura en la literatura árabe, con Prólogo de Antonio FERNÁNDEZ ALBA, Madrid, ed. Hiperión, 1988, 2. ${ }^{\mathrm{a}}$ ed., $196 \mathrm{pp}$.

4.027 RUBIERA MATA, M. " Jesús: «El Baix Vinalopó durant l'època àrab», La Rella, Elx, n. ${ }^{\circ}$ 6, juny 1988, pp. 49-56.

4.028 RUBIERA MATA, M. ${ }^{a}$ Jesús: Bibliografía de la Literatura HispanoÁrabe, Alicante, Universidad, 1988, 75 pp.

4.029 RUB!ERA MATA, M. ${ }^{\text {a }}$ Jesús: "La conquesta de València per Jaume I com a tema literari en un testimoni de l'esdeveniment: Ibn Al-Abbâr de València», L'Aiguadolç. Dossier: La Conquesta de València (1238), Marina Alta, tardor 1988, pp. 33-47.

4.030 RUBIERA MATA, M. a Jesús: "La función estética del agua en la civilización arabigoislámica", Agua y poblamiento musulmán. Aigüa i poblament musulmà (Simposium de Benissa, abril 1987). Benissa, ed. Ajuntament, 1988, pp. 11-12.

4.031 RUBIERA MATA, M. ${ }^{a}$ Jesús: "Las inscripciones árabes de Játiva: una hipótesis y una propuesta sobre la denominación de un estilon, Homenaje al Profesor Darío Cabanelas Rodríguez, O.F.M., con motivo de su LXX Aniversario, Granada, Universidad, 1987, vol. II, pp. 292-295.

4.032 RUBIERA MATA, M. ${ }^{a}$ Jesús: «La lengua romance en las jarchas (Una jarcha en lengua occitana)", Al-Qantara, Madrid, C.S.I.C., n. ${ }^{\circ}$ VIII/1-2, 1987, pp. 319-329.

4.033 RUBIERA MATA, M. Jesús: «Muhammad Benissa "Ben Al-Labbana" i els coloms", Revista de Festes, Benissa, 1988, 1 pág..

4.034 RUBIERA MATA, M. ${ }^{a}$ Jesús: «Los precedentes geopolíticos musulmanes del Señorío de Villena, Congreso de Historia del Señorío de Villena, Albacete, Instituto de Estudios Albacetenses / C.S.I.C. I C.E.C.E.L., 1987, pp. 356-360.

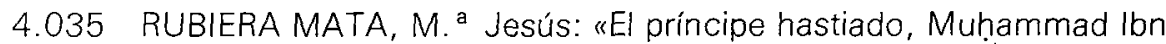
"Abdalmalik Ibn Abi ' ${ }^{\circ} \bar{A}$ mir, efímero soberano de Orihuela y Murcia", Sharq Al-Andalus. Estudios Árabes, Alicante, n. ${ }^{\circ} 4,1987$, pp. 72-82.

4.036 RUBIERA MATA, M. ${ }^{a}$ Jesús; MARTÍNEZ, Vicent: "Versions de poesia aràbigo-valenciana: Ibn Khafaja d'Alzira (1058-1139)" Trenc d'Alba, Alicante, n. ${ }^{\circ}$ 2, 1988, pp. 21-25.

4.037 RUBIO GOMIS, Federico: "Catálogo de yacimientos y materiales altomedievales y musulmanes", L'Ull del Moro, Alcoy, II, 1988, 162 pp.

4.038 RUBIO VELA, Agustín: "Don Juan Manuel, Valencia y el comercio con Castilla en la primera mitad del siglo XIV", Boletín de la Sociedad Castellonense de Cultura, Castelión de la Plana, LXIII/III, jul.-sept. 1988, pp. 391-415. Conflictos con musulmanes de Xirell. 
4.039 RUZAFA GARCÍA, M.: El asalto a la morería de Valencia (s. XV), Memoria de Licenciatura leída en la Universidad de Valencia en 1982.

4.040 RUZAFA GARCÍA, M.: "La Morería de Valencia», Historia del Pueblo Valenciano, Valencia, ed. por el Diario LEVANTE, n. ${ }^{\circ} 10,1989$, pp. 319-320.

\section{$\mathrm{S}$}

4.041 SALVADOR ESTEBAN, Emilia: Felipe $/ /$ y los moriscos valencianos. Las repercusiones de la revuelta granadina (1568-1570), Valladolid, 1988, 59 pp.

4.042 SAN MARTÍN MORO, P. A.: «Nuevas aportaciones al plano arqueológico de Cartagena", Museo de Zaragoza. Boletín. Homenaje a Antonio Beltrán, Zaragoza, n. ${ }^{\circ} 4,1985$, pp. 131-149. Sin referencias a la Cartagena árabe, "medieval".

4.043 SÁNCHEZ FERRER, José: Alfombras antiguas de la provincia de Albacete, Albacete, Instituto de Estudios Albacetenses, 1986, $510 \mathrm{pp}$. Reseñado por Pedro J. LAVADO PARADINAS en el Boletín de la Asociación Española de Orientalistas, Madrid, XIII, 1987, pp. 414-416. Alfombras ya famosas desde la época islámica.

4.044 SÁNCHEZ FERRER, José: "Apuntes para una historia de la manufactura textil de la provincia de Albacete (siglos XIII al XVI) «, Cultural Albacete, Albacete, n. ${ }^{\circ}$ 4, mayo de 1986, pp. 3-16.

4.045 SÁNCHEZ TRUJILLANO, M. ${ }^{a}$ Teresa: "Cerámica hispanomusulmana y mudéjar de Nájera", Arqueología Medieval Española. I Congreso. Madrid, 19-24 enero 1987. Tomo II: Comunicaciones, Madrid, ed. por la Conserjería de Cultura de la Comunidad de Madrid / Asociación Española de Arqueología Medieval, 1987, pp. 157-165. Provincia de La Rioja.

4.046 SANMIGUEL MATEO, Agustín: «Sobre una torre desaparecida contigua a la iglesia de Santas Justa y Rufina en Maluenda (Zaragoza)», Tvriaso. Monográfico "El Islam en Aragón", Tarazona, Centro de Estudios Turiasonenses de la Institución «Fernando el Católico» del C.S.I.C., n. ${ }^{\circ} 7,1987$, pp. 105-113. Torre mudéjar.

4.047 SEBASTIÁN FABUEL, Vicente: "El "Castell d'Almizra", Campaña de 1985". Arqueología Medieval Española. II Congreso. Madrid, 19-24 enero 1987. Tomo II: Comunicaciones, Madrid, ed. por la Conserjería de Cultura de la Comunidad de Madrid / Asociación Española de Arqueología Medieval, 1987, pp. 167-179.

4.048 SELLS, M.: «lbn 'Arabī's polished mirror: perspective shift and meaning event", Studia Islamica, París, n. ${ }^{\circ}$ XVII, 1988, pp. 121-150.

4.049 SÉNAC, Ph.: "Présence musulmane en Languedoc. Realités et vestiges", Cahiers de Fanjeaux. Islam et Chrétiens du Midi (XIIe.-XIVe. s.), Fanjeaux-Toulousse, C.N.R.S., n. ${ }^{\circ} 18,1983$, pp. 43-57. 
4.050 SOLÁ, E.: Un Mediterráneo de piratas: corsarios, renegados y cautivos, Madrid, 1988, $222 \mathrm{pp}$.

4.051 SOTO I COMPANY, Ricard: "Sobre els molins d'origen musulmà a Banyalbufar", Bolleti de la Societat Arqueològica Lul-liana, Palma de Mallorca, n. ${ }^{\circ} 43,1987$, pp. 193-194.

4.052 SOUTO LASALA, Juan Antonio: "Un aspecto concreto de las campañas omeyas contra la Marca Superior de Al-Andalus: El campamento de 'Abdarraḥmān III ante Zaragoza (935-937). Observaciones a propósito de una hipótesis», Boletín de la Asociación Española de Orientalistas, Madrid, XIII, 1987, pp. 333-346.

4.053 SOUTO LASALA, Juan Antonio: «La escavación arqueológica del Patio de San Martín de La Aljafería (febrero-mayo de 1985): llustraciones", Sharq Al-Andalus. Estudios Árabes, Alicante, n. ${ }^{\circ} 4,1987$, pp. 231-233.

4.054 SOUTO LASALA, Juan Antonio: "La puerta de entrada en La Aljafería en época taifa a la luz de las excavaciones realizadas en 1985", Arqueología Medieval Española. II Congreso. Madrid, 19-24 enero 1987. Tomo II: Comunicaciones, Madrid, ed. por la Conserjería de Cultura de la Comunidad de Madrid / Asociación Española de Arqueología Medieval, 1987, pp. 273-280.

4.055 STALS, William C.: "Aragonese Exarici in the Twelft Century: Their Status and Conditions of Landholding", Sharq Al-Andalus. Estudios Árabes, Alicante, n. ${ }^{\circ} 4,1987$, pp. 131-144.

4.056 SUGRANYES DE FRANCH, R.: «L'Àpologétique de Raymond Lulle visà-vis de I'Islam», Cahiers de Fanjeaux. Islam et Chrétiens du Midi $\left(X \|^{e}\right.$.-XIVe. s.), Fanjeaux-Toulousse, C.N.R.S., n. ${ }^{\circ} 18,1983$, pp. 373-394.

\section{T}

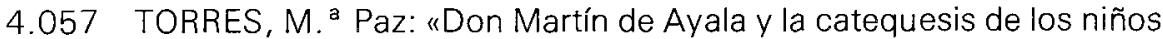
moriscos", Homenaje al Profesor Darío Cabanelas Rodríguez, O.F.M., en su LXX Aniversario, Granada, Universidad, vol. I, 1987, pp. 509-517.

4.058 TORRES BALBAS, Leopoldo: Ciudades Hispano-Musulmanas, Madrid, Instituto Hispano-Árabe de Cultura / Ministerio de Asuntos Exteriores, $1985,2^{\text {a }}$ ed., $694 \mathrm{pp}$.

4.059 TORRES FONTES, Juan: «Apellido y cabalgada en la frontera de Granada», Estudios de Historia y Arqueología Medievales, Cádiz, n. ${ }^{\circ} \mathrm{V}$ VI, 1985-86, pp. 177-190. Documentos murcianos, siglos XIV-XV.

4.060 TORRES FONTES, Juan: "Documentos para comentar", Homenaje al Profesor Muñoz Cortés, Murcia, Universidad, 1976-77, vol. II, pp. 743-763.

4 OG1 TORRES FONTES, Juan: La reconquista de Murcia en 1266 por Jai- 
me I de Aragón, Murcia, Academia Alfonso X el Sabio, 1987, 2. ${ }^{\text {a }}$ ed., 209 pp.

4.062 TORRES FONTES, Juan: Repartimento de Orihuela, Murcia, Academia Alfonso X el Sabio / Patronato Ángel García Rogel, 1988, 213 pp.

4.063 TORRÓ I ABAD, Josep; IVARS PÉREZ, Josep: «Despoblados del País Valenciano (siglo XIII-XVII). Para una arqueología del asentamiento agrario", Arqueología Medieval Española. II Congreso. Madrid, 19-24 enero 1987. Tomo II: Comunicaciones, Madrid, ed. por la Conserjería de Cultura de la Comunidad de Madrid / Asociación Española de Arqueología Medieval, 1987, pp. 741-752.

4.064 TORRÓ I ABAD, Josep; SEGURA I MARTÍ, Josep M. ${ }^{a}$ : «Irrigación y asentamientos en la Vall de Perputxent", Agua y poblamiento musulmán. Aigüa y poblament musulmà (Simposium de Benissa, abril 1987), Benissa, ed. Ajuntament, 1988, pp. 67-92.

4.065 TRENCHS ODENA, José: «Les "Alexandrini", ou la désobedience aux embargos conciliares ou pontificaux contre les Musulmans", Cahiers de Fanjeaux. Islam et Chrétiens du Midi (XIIe.-XIVe. s.), FanjeauxToulousse, C.N.R.S., n. ${ }^{\circ}$ 18, 1983, pp. 169-193.

4.066 TRENCHS ODENA, José: "Los correos regios bajo Jaime I (1255-1276), Cuadernos de Historia "Jerónimo Zurita", Zaragoza, pp. 45-46, 1983, pp. 153-158. Dos correos musulmanes. Tenían sueldo especial para alojarse fuera de las dependencias reales.

4.067 TREPPO, Mario: Els mercaders catalans i l'expansió de la Corona Catalano-Aragonesa al segle XV, Barcelona, 1984, 578 pp. Expansión mediterránea del comercio catalán.

\section{V}

4.068 VV. AA.: Indices de las revistas españolas de arabismo. I. Autores (A-M), Madrid, Instituto Hispano-Árabe de Cultura, 1987, pp. 64-109 (Cuadernos de la Biblioteca Islámica "Félix María Pareja", n. ${ }^{\circ} 8$ ).

$4.069 \mathrm{VV}$. AA.: Indices de las revistas españolas de arabismo. II. Autores (A-M), Madrid, Instituto Hispano-Árabe de Cultura, 1987, pp. 64-109 (Cuadernos de la Biblioteca Islámica "Félix María Pareja”, n. ${ }^{\circ} 9$ ).

4.070 VALLEJO ZAMORA, José: "Los moriscos de Torrellas entre 1495-1610: Consideraciones demográficas", Tvriaso. Monográfico "El Islam en Aragón», Tarazona, Centro de Estudios Turiasonenses de la Institución «Fernando el Católico» del C.S.I.C., n. ${ }^{\circ} 7,1987$, pp. 282-324.

4.071 VENTURA, Agustí: "Alqueríes medievals a la Vall d'Albaida», Ontinyent. Fiestas de la Puríssima, 1988, Ontinyent, 1988, pp. 25-37.

4.072 VENY, J.: «Origen dels cognoms catalans Mirabent i Parcet», Miscel-lània d'homenatge a Enric Moreu-Rey, Montserrat, Publicacions de l'Abadia de Montserrat, vol. I, 1988, pp. 281-295. 
4.073 VERONNE, Chantal de la: "Un intento de Alianza entre España y Argel en 1701 ", Al-Qanțara, Madrid, n. ${ }^{\circ}$ VIII, pp. 135-151.

4.074 VERLINDEN, Charles: "Les esclaves musulmans du Midi de la Francen, Cahiers de Fanjeaux. Islam et Chrétiens du Midi (XI/e. -XIVe. s.), Fanjeaux-Toulousse, C.N.R.S., n. ${ }^{\circ}$ 18, 1983, pp. $215-234$.

4.075 VERLINDEN, Charles; GUIRAL, Jacqueline: València un mercat medieval, Valencia, Excma. Diputació Provincial, 1985.

4.076 VERNET, Juan: Al-Andalus: El Islam en España, Barcelona, ed. Junwerg, 1987, $233 \mathrm{pp}$.

4.077 VICENT I CORTINA, Vicent: "La conquesta de Montcada en la "Crònica" de Jaume [n, XVI Asamblea de Cronistas Oficiales del Reino de Valencia (Valencia, 9, 10, 11 y 12 octubre 1986), coord. por Santiago BRU I VIDAL, Valencia, ed. por la Consellería de Cultura / Diputación Provincial / Ayuntamiento de Valencia, 1988, vol. I, pp. 513-518.

4.078 VILADÉS CASTILLO, José María: "Cerámica Islámica con decoración estampillada de Zaragoza", Arqueología Medieval Española. II Congreso. Madrid, 19-24 enero 1987. Tomo 1I: Comunicaciones, Madrid, ed. por la Conserjería de Cultura de la Comunidad de Madrid / Asociación Española de Arqueología Medieval, 1987, pp. 221-230.

4.079 VILAR, Juan Bautista: «Inserción de los españoles en la sociedad urbana y en la sociedad rural de la Oranie (Argelia francesa) (1880-1930)», Africa, Roma, XVII/4, diciembre 1987, pp. 556-569.

4.080 VILLANOVE, Jean: Histoire populaire dels Catalans. Des origines au XVe. siècle, Perpiñán, 1986, 4. ${ }^{a}$ ed., 345 pp. Árabes, pp. 66-72.

4.081 VILLEGAS, Marcelino: "Un enigmático término cervantino", Sharq AlAndalus. Estudios Árabes, Alicante, n. ${ }^{\circ} 4$, 1987, pp. 249-251.

4.082 VILLENA, Leonardo: "Noticias históricas y técnicas de la Hoz del Júcar y sus castillos», Congreso de Historia del Señorío de Villena, Albacete, Instituto de Estudios Albacetenses / C.S.I.C. / C.E.C.E.L., 1987, pp. 423-433.

4.083 VIRGILI, Antoni: "Conquesta, colonització i feudalització de Tortosa (segle XII) segons el Cartulari de la Catedral», Estudi General. La formació i expansió del feudalisme català. Actes del Col-loqui organitzat pel Collegi Universitari de Girona (8-11 de gener de 1985). Homenatge a Santiago Sobrequés i Vidal, ed. a cura de Jaume PORTELLA I COMAS, Girona, n. ${ }^{\circ} 5-6$, any 1985-86, pp. 275-279.

\section{W}

4.084 WAGNER DE AL-GANABI, Wilhelmina T. F.: La escuela coránica de Denia: Abū ${ }^{c} A m r{ }^{\complement} U t m a ̄ n ~ b . ~ S a^{c} \bar{T} d$ de Denia. Figura, obra formativa y obra escrita, Tesis Doctoral leída en la Univarsidad de Granada, 1774 pp. 
4.085 WOLLF, Ph.: «Guerre entre pays de langue d'Oc et Occident musulman", Cahiers de Fanjeaux. Islam et Chrétiens du Midi (XIIe.-XIVe. s.), Fanjeaux-Toulousse, C.N.R.S., n. ${ }^{\circ} 18,1983$, pp. $29-42$.

\section{Z}

4.086 ZAYD, Rhona: "The Muslim/Mudejar in the Cantigas de Alfonso $\mathrm{X}$ el Sabio», Sharq Al-Andalus. Estudios Árabes, Alicante, n. ${ }^{\circ} 4,1987$. pp. 145-152. 